\title{
Using the Multi-Theory Model (MTM) of Health Behavior Change to Explain the Correlates of Mammography Screening among Asian American Women
}

\author{
Manoj Sharma ${ }^{1}{ }^{\mathbb{D}}$, Chia-Liang Dai ${ }^{2}$, Kavita Batra ${ }^{3, *} \mathbb{D}$, Ching-Chen Chen ${ }^{4}$, Jennifer R. Pharr ${ }^{1} \mathbb{D}$, \\ Courtney Coughenour ${ }^{1}$ D, Asma Awan ${ }^{5}$ and Hannah Catalano 6
}

1 Department of Environmental and Occupational Health, School of Public Health, University of Nevada, Las Vegas, NV 89119, USA; manoj.sharma@unlv.edu (M.S.); Jennifer.pharr@unlv.edu (J.R.P.); courtney.coughenour@unlv.edu (C.C.)

2 Department of Teaching and Learning, College of Education, University of Nevada, Las Vegas, NV 89154, USA; chia-liang.dai@unlv.edu

3 Office of Research, Kirk Kerkorian School of Medicine, University of Nevada, Las Vegas, NV 89102, USA

4 Department of Counselor Education, School Psychology, and Human Services, College of Education, University of Nevada, Las Vegas, NV 89154, USA; ching-chen.chen@unlv.edu

5 Department of Health Informatics, School of Health Sciences, Purdue University, West Lafayette, IN 47906, USA; asmaawan@student.purdueglobal.edu

6 School of Health and Applied Human Sciences, University of North Carolina Wilmington, Wilmington, NC 28403, USA; catalanoh@uncw.edu

check for updates

Citation: Sharma, M.; Dai, C.-L.; Batra, K.; Chen, C.-C.; Pharr, J.R.; Coughenour, C.; Awan, A.; Catalano, H. Using the Multi-Theory Model (MTM) of Health Behavior Change to Explain the Correlates of Mammography Screening among Asian American Women. Pharmacy 2021, 9, 126. https://doi.org/ $10.3390 /$ pharmacy 9030126

Academic Editor: Yifei Liu

Received: 23 June 2021

Accepted: 13 July 2021

Published: 15 July 2021

Publisher's Note: MDPI stays neutral with regard to jurisdictional claims in published maps and institutional affiliations.

Copyright: (c) 2021 by the authors. Licensee MDPI, Basel, Switzerland. This article is an open access article distributed under the terms and conditions of the Creative Commons Attribution (CC BY) license (https:// creativecommons.org/licenses/by/ $4.0 /)$.
* Correspondence: Kavita.batra@unlv.edu

\begin{abstract}
Globally, breast cancer is the most common malignancy affecting women. The incidence of breast cancer has been growing among Asian American women. Mammography is a screening procedure that provides early diagnosis for the timely treatment to reduce premature mortality due to breast cancer. However, there are no national data available that summarize the rates of mammography screening among Asian American women. Some small-scale studies have reported low rates of mammography uptake among Asian American women. This cross-sectional study utilized the fourth-generation, multi-theory model (MTM) of health behavior change to explain the correlates of mammography screening among Asian American women between the ages of 45-54 years. A 44-item instrument was evaluated for face, content, and construct validity (using structural equation modeling) and reliability (Cronbach's alpha) and administered electronically to a nationally representative sample of Asian American women $(n=374)$. The study found that Asian American women who have had received mammograms in the past 12 months as per recommendations, all three constructs of MTM, namely, participatory dialogue $(\beta=0.156, p<0.05)$, behavioral confidence $(\beta=0.236, p<0.001)$, and changes in the physical environment $(\beta=0.426, p<0.001)$ were statistically significant and crucial in their decision to initiate getting a mammogram, accounting for a substantial $49.9 \%$ of the variance in the decision to seek mammography. The study also found that the MTM constructs of emotional transformation $(\beta=0.437, p<0.001)$ and practice for change $(\beta=0.303$, $p<0.001$ ) were significant for maintaining the repeated behavior of getting annual mammograms and were responsible for $53.9 \%$ of the variance. This evidence-based study validates the use of MTM in designing and evaluating mammography screening promotion programs among Asian American women aged $45-54$ years.
\end{abstract}

Keywords: mammography; multi-level theory; screening; behavior; Asian American

\section{Introduction}

Globally, cancer is the second leading cause of mortality accounting for approximately 9.6 million deaths [1]. Breast cancer is the most common malignancy affecting women worldwide [2]. In the United States (U.S.), breast cancer is the most commonly diagnosed 
cancer after skin cancers, with one in eight (13\%) women being diagnosed with an invasive type of breast cancer during their lifetime [3]. According to the American Cancer Society's [4] recent projected estimates, there will be approximately 284,200 new cases and 44,130 deaths attributed to breast cancer in the U.S. in 2021. The differential risk of breast cancer by nativity, racial, and ethnic characteristics was also reported with Asian American women bearing a disproportionate burden $[5,6]$.

The incidence of breast cancer has been growing with a rate of 94 cases per 100,000 among Asian American women residing in the U.S. [5,7]. Previous reports confirmed that the odds of survival were associated with the Asian ethnicity overall [8]. An analysis of this limited SEER registry data from 2019 indicated that there was a total of 47,401 Asian/Pacific Islander women diagnosed with invasive breast cancer between 2012 and 2016 [3]. With regard to the nativity of Asian American women, 132 cases of women with diagnosed breast cancer were compared with 438 Asian American without breast cancer diagnosis [6]. The results of the study suggested that the breast cancer risk is higher among immigrant Asian American women compared with their US-born counterparts or those who have lived less than $50 \%$ of their life in the U.S. [6]. The rate of survival also varied across racial and ethnic groups, which highlights the need of detecting breast cancers at an early stage with the help of primary and secondary levels of prevention, including awareness and screening.

Mammography is a screening procedure that provides early diagnosis, which can lead to treatment and reduced premature mortality due to breast cancer (Centers for Disease Control \& Prevention (CDC)) [9]. However, the use of mammograms as a screening method is still a debatable issue due to the problems of false positives, over-diagnosis, and overtreatment [10]. Additionally, health authorities differ in their stances on mammography recommendations across age groups. Four primary authorities in the U.S. proposed guidelines on mammography: American College of Obstetricians and Gynecologists (ACOG), U.S. Preventive Services Task Force, American Cancer Society (ACS), and National Comprehensive Cancer Network (NCCN) [11]. There seems to be some general agreement in these four sets of guidelines that women ages $45-54$ years should undergo annual mammograms, and this guideline was used for our study.

To our best knowledge, there are no national data available that summarize the rates of mammography screening among Asian American women through a country-wide population-based survey. However, some small-scale studies have reported low rates of mammography uptake [12]. For instance, a study of Korean American women reported that $22.2 \%$ of women ages $45-49$ years and $29 \%$ of women ages $50-54$ years had a mammogram in the past year [12]. According to a 2008 Behavioral Risk Factor Surveillance System (BRFSS) data-based study, $60.3 \%$ of Asian American women over the age of 40 years had mammograms in the past year, which was the lowest among all the groups studied [13]. However, the estimates of mammography uptake or utilization are not yet available. Some studies reported regional differences across the U.S. for the mammography screening rates among Asian American women. For instance, a pooled weighted data analysis from five cycles of the California Health Interview Survey conducted between 2001 and 2009, reported an increase in mammograms across all ages in Asian American women from $76-82 \%$ from 2001 to 2009 [14]. There is a caveat to this finding; the response rate to this survey was quite low (17.7\% to $37.7 \%$ in different cycles), which emphasizes the need to conduct additional research pertaining to mammography screening utilization among Asian American women. The Asian American community is increasing rapidly in the U.S. and the present healthcare system and health research are not catering to the needs of this diverse community [13]. In order to meet the growing needs and address the gap in the literature for this underserved minority group, this study is being undertaken [13]. The findings of this study will help in designing behavior change interventions to increase mammography uptake or utilization among Asian American women.

Several factors were known to affect the utilization of mammography screening among Asian American women. Some determinants that are associated with increased rates of 
mammography screening in Asian American women are having (1) U.S. citizenship [15], (2) longer residency in the U.S. [14,16], (3) a college education [14,17], (4) knowledge of the guidelines [16], (5) health insurance [13,14], (6) a primary care provider who recommended a mammogram [17-19], (7) a routine health check-up in the past year [13], and (8) knowing someone with a history of breast cancer and/or having undergone mammography [16]. Some factors that are barriers to getting mammograms among Asian American women are (1) being of Muslim religion [19,20], (2) perceived religious discrimination [19], (3) impingement on modesty [19], (4) being less acculturated [21], and (5) logistical barriers [22]. It is important to note that not all Asian Americans are a monolithic entity and there are variations among the determinants based on national origin.

There are few interventions that promote mammography among Asian American women. Some of the intervention approaches that have been used are the patient navigator care management model [23], community workshops [24], medical interpretation services for limited English proficiency patients [25], use of primary care providers [26], religiously tailored interventions [27,28], store-based education [29], web-based education delivery [30] among others. Further, very few studies have used behavioral theories as a basis for these interventions. For instance, Boxwala and colleagues [17] and Lee and colleagues [30] used the health belief model, Wu and West [31] used the transtheoretical model, and Sun and colleagues [32] used the prospect theory. Non-theory-based approaches and utilization of older theories do not improve the predictability of the health behavior change. Such approaches lead to doing "same old same old" without advancement of the scientific discipline of health behavior research (HBR). Furthermore, most of the older approaches were about behavior acquisition and newer fourth-generation approaches have been developed that promote behavior "change" instead of mere acquisition and lead to development of precision interventions $[33,34]$. The first-generation models were about knowledge transfer, the second-generation models were about skill acquisition, third generation models were about behavior acquisition, and the fourth-generation models are about behavior change utilizing constructs from multiple evidence-based theories [33,34]. Therefore, there is a need to utilize recent fourth-generation health behavior change models to explain the correlates of mammography screening and design precise interventions to promote mammography in this understudied and underserved population of Asian American women.

One emerging fourth-generation model is the multi-theory model (MTM) of health behavior change $[33,34]$. This model breaks down the complex health behavior change into two components of initiation and maintenance with three explanatory constructs for each of the two components (Figure 1). This model has been used in qualitative [35,36], cross-sectional [37-40], and experimental studies [41-43] with a variety of behaviors in different priority populations but has not been applied to understanding mammography screening behaviors. Therefore, the current study aims to utilize the multi-theory model (MTM) of health behavior change to explain the correlates of mammography screening in a sample of Asian American women between the ages of 45-54 years. 


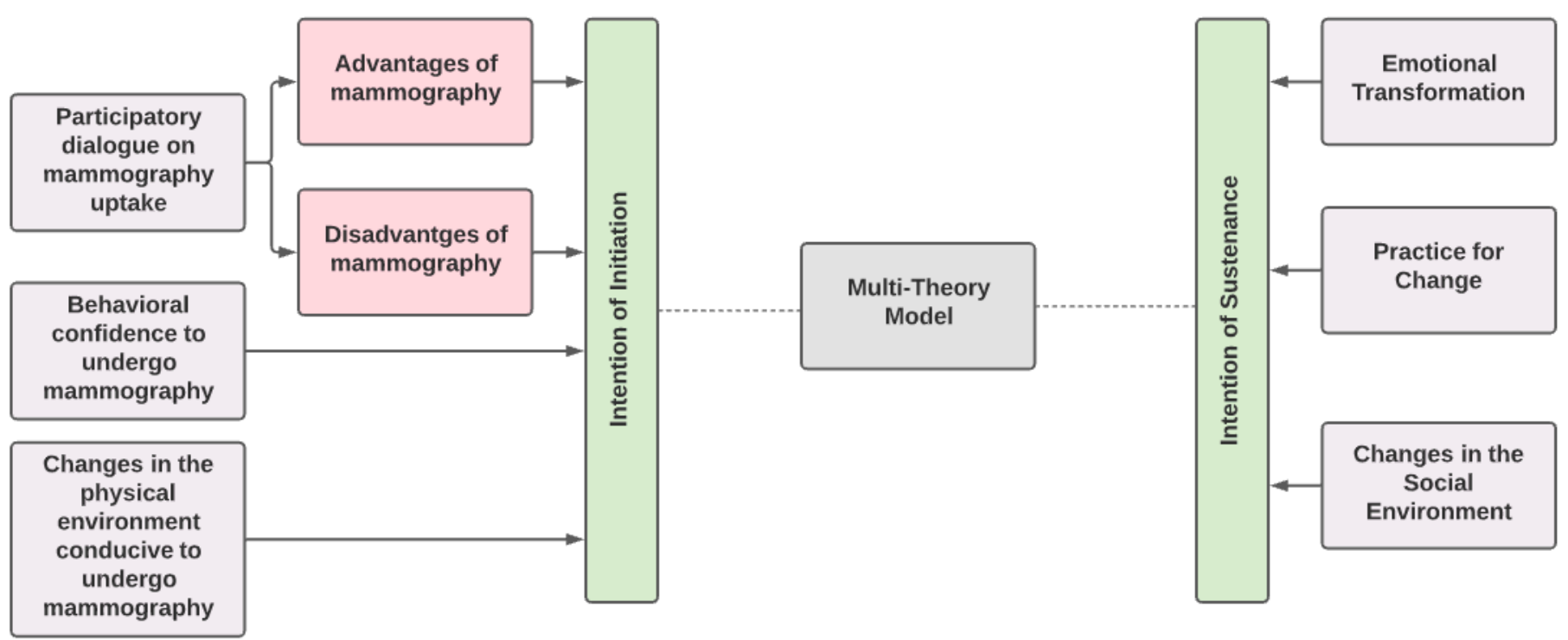

Covariates: Age, Asian subgroups, Education, U.S. residency, Health insurance

Figure 1. Conceptual model of Multi-Theory Model.

\section{Materials and Methods}

\subsection{Study Design and Data Collection}

The data collection for this cross-sectional study was conducted from 10 March 2021 through 18 March 2021, utilizing a research panel of participants facilitated by the market research firm Qualtrics [44]. Qualtrics ${ }^{\circledR}$ (the world's leading enterprise survey technology solution and XM platform) has been providing samples for over a decade now. Qualtrics partners with over 20 online sample providers to recruit a research panel of participants, which has been created via convenience sampling to build samples from multiple sources. This enable researchers with the diverse and representative datasets. The sample partners randomly select respondents, who are likely to qualify. The majority of the samples come from traditional, actively managed, panel portals. Occasionally, social media is used to gather respondents. For inaccessible groups, Qualtrics utilizes niche panels via special recruitment campaigns [45]. The survey invitations are intentionally kept general to prevent the self-selection bias. Depending upon the study's inclusion criteria, Qualtrics adds screening questions in the beginning of the survey to ensure inclusion of eligible participants. All qualifying participants who complete the survey are compensated in accordance with Qualtrics ${ }^{\circledR}$ panel agreement. The agreement varies and may include cash, airline miles, charitable donations, sweepstakes entrance, vouchers, gift certificate, etc. Additional information about ethical, methodological, and regulatory guidelines can be found at www.esomar.org (accessed on 8 July 2021). Previous studies have provided the detailed information related to the use of Qualtrics ${ }^{\circledR}$ research panel platforms [45].

\subsection{Ethical Considerations}

The study (protocol \#1727672-1, dated 4 March 2021) was considered an exempt research study by the Institutional Review Board (IRB). Participation in the study was completely voluntary, and detailed information about the study's objectives and significance were provided to participants in an informed consent attached with the web-based survey. Personal identifiers, including name and email address, were not collected to preserve anonymity. Only one response per participant was allowed. We used the "Prevent 
Ballot Box Stuffing" feature in the Qualtrics to restrict multiple responses from the same participant. This feature is driven by a strong algorithm to ensure data integrity and unique responses. Additionally, Qualtrics utilizes digital fingerprinting technology to preserve integrity of the survey.

\subsection{Data Intergrity}

Data for this study were collected by Qualtrics Research Services as a part of the contractual agreement. As an essential part of the contract, all data privacy laws and regulations were followed to preserve data integrity. Qualtrics database does not hold confidential information of the respondents or panelists. Qualtrics ${ }^{\circledR}$ provided deidentified data to the researchers in an excel sheet, which was stored on a password protected desktop computer in a locked office. Only the principal investigator and statistician of this study had access to the deidentified data files.

\subsection{Survey Questionnaire}

Based on MTM, a 44-item survey questionnaire was developed to determine the correlates of mammography screening uptake among Asian American women aged 45-54 years. The survey was composed of 13 demographic questions and mammography history, and 31 items for the two primary MTM theoretical constructs (initiation and sustenance). A panel of eight subject matter experts (SMEs), investigated face and content validity of the questionnaire in several rounds of review. The reviews were blinded to prevent observer bias. Several revisions were performed to enhance readability and content of the questionnaire. A detailed description of the instrument's domains and constructs is provided in Table 1.

Table 1. Domains and constructs of MTM theoretical framework.

\begin{tabular}{|c|c|c|c|c|c|}
\hline Domain & Constru & & $\begin{array}{c}\text { Definition (s) and Examples from } \\
\text { This Study }\end{array}$ & $\begin{array}{l}\text { Number } \\
\text { of Items }\end{array}$ & $\begin{array}{l}\text { Possible Range } \\
\text { (Min-Max) }\end{array}$ \\
\hline \multirow{4}{*}{$\begin{array}{l}\text { Intention of } \\
\text { Initiation }\end{array}$} & \multirow{2}{*}{$\begin{array}{l}\text { Participatory dialogue } \\
\text { (Derived after } \\
\text { subtracting summative } \\
\text { score of disadvantages } \\
\text { from advantages) }\end{array}$} & Advantages & $\begin{array}{l}\text { Perception of advantages following } \\
\text { the specific behavior initiation, e.g., } \\
\text { early detection, peace of mind, etc. }\end{array}$ & 5 & $0-20$ units \\
\hline & & Disadvantages & $\begin{array}{l}\text { Perception of disadvantages } \\
\text { following the specific behavior } \\
\text { initiation, e.g., invasion of modesty, } \\
\text { inconvenience, etc. }\end{array}$ & 5 & $0-20$ units \\
\hline & \multicolumn{2}{|c|}{ Behavior confidence } & $\begin{array}{l}\text { Surety of behavior despite external } \\
\text { and internal driving factors, e.g., } \\
\text { overcoming cost, overcoming } \\
\text { discomfort, etc. }\end{array}$ & 5 & $0-20$ units \\
\hline & \multicolumn{2}{|c|}{ Changes in the physical environment } & $\begin{array}{l}\text { Overcoming enabling factors for } \\
\text { behavior initiation, e.g., easy access } \\
\text { to a place, ability to get it when one } \\
\text { wants it, etc. }\end{array}$ & 3 & $0-12$ units \\
\hline \multirow{3}{*}{$\begin{array}{l}\text { Intention of } \\
\text { Sustenance }\end{array}$} & \multicolumn{2}{|c|}{ Emotional transformation } & $\begin{array}{l}\text { Converting emotions into intention, } \\
\text { e.g., directing feelings into goal, } \\
\text { self-motivation, etc. }\end{array}$ & 3 & $0-12$ units \\
\hline & \multicolumn{2}{|c|}{ Practice for change } & $\begin{array}{l}\text { Continuous adaptation for behavior } \\
\text { changes, e.g., monitoring, } \\
\text { overcoming barriers, etc. }\end{array}$ & 3 & $0-12$ units \\
\hline & \multicolumn{2}{|c|}{ Changes in the social environment } & $\begin{array}{l}\text { Using social cues for behavior } \\
\text { change, e.g., support from family, } \\
\text { friends, etc. }\end{array}$ & 5 & $0-20$ units \\
\hline
\end{tabular}




\subsubsection{Intention of Initiation}

Constructs of advantages and disadvantages of intention of initiation were measured on a 5-point Likert scale, which ranges from "strongly disagree" to "strongly agree."

The score of Participatory dialogue was derived by subtracting the summative score of disadvantages from advantages. The other two constructs of intention to initiation were behavioral confidence and changes in the physical environment. These were also measured on 5-point Likert scale of surety, which had the response options of Not at all sure (0), slightly sure (1), moderately sure (2), very sure (3), completely sure (4). A high score was associated with the likelihood of initiation of behavior change.

\subsubsection{Intention of Sustenance}

Constructs of emotional transformation, practice for change, and changes in the social environment were measured on a 5-point Likert scale of surety, which has the response options of Not at all sure (0), slightly sure (1), moderately sure (2), very sure (3), completely sure (4). A high score was associated with the likelihood of sustenance of behavior change. Additionally, two items were used to model initiation and sustenance, which were measured as scale variables.

\subsection{Statistical Analysis}

We used IBM SPSS version 27.0 (IBM Corp. Armonk, NY, USA), Mplus 7.11, and G* Power software packages for the analyses. Minimum sample size was estimated using the Cohen's effect sizes conventions (based on the type of statistical test) corresponding to $99 \%$ power $[46,47]$. The significance level was set at 0.05 , and $95 \%$ confidence intervals were reported wherever appropriate. Data normality assumptions were assessed through visual inspection of normal Q-Q plots and histograms. An independent-samples t-test was utilized to compare the mean scores of MTM constructs across groups who have had mammography and those who have not. Categorical variables were expressed as counts and proportions, whereas continuous variables were represented as means and standard deviations. Two separate Hierarchical Regression Models (HRM) were built to predict the variance in the likelihood of initiation and sustenance of mammography behavior by multiple factors, such as demographic characteristics and MTM constructs.

For construct validation, Structural Equation Modelling (SEM) was utilized to determine the structural relationship between measured variables and latent constructs. Weighted least squares approach (WLSMV estimator) and the 0.05 alpha level were used to test our two hypothesized structural models among the samples. Drawing upon the theory and prior research, our hypothesized model included participatory dialogue (advantages and disadvantages), behavioral confidence, changes in physical environment, changes in social environment, practice for change, and emotional transformation as independent variables; and initiation and sustenance of health behavior change as dependent variables. We hypothesized that (1) the variables of participatory dialogue (advantages and disadvantages), behavioral confidence, and changes in physical environment constructs would impact the initiation of mammography screening behavior change, and (2) the changes in social environment, practice for change, and emotional transformation constructs would impact the sustenance of mammography screening behaviors. This study used a variety of fit indices because they provide different information about model fit. We considered the substantive meaningfulness of the model, significant $\chi^{2}$ statistics as evidence that models did not fit the data exactly [48], Tucker-Lewis (TLI) and comparative fit (CFI) indices greater than 0.95 evidence of good fit [48-50], and root means square error of approximation (RMSEA) values of less than 0.05 to be acceptable [51]. To estimate the sample size for testing hypothesized models, we first sought to meet the conventional 10 subjects per variable ratio [52-54]. Next, sample size calculation for Structural Equation Modeling [55] recommended a minimum of 137 participants were required to achieve a statistical power level of 0.8 at an alpha level of 0.05 with 0.3 (medium) anticipated effect size and number of variables in the models. Finally, previous studies suggested that, for 
confirmatory factor analysis, this sample size was sufficiently powered to evaluate the hypothesized models [56-58].

\section{Results}

A total of 374 participants completed this study. The mean age of the study sample was 49.25 (SD: 2.68) years. Chinese Americans represented $41.2 \%$ of the sample. The majority of participants (69.3\%) were employed, working 34.9 average hours per week. The percentage of participants with health insurance coverage was $93 \%$, over $60 \%$ of the population had a household income under $\$ 100,000$ and lived in suburban neighborhoods. Forty percent of participants reported their religious affiliation as Christianity and $68.7 \%$ of the women were married (Table 2).

Table 2. Demographic characteristics of the sample population $(n=374)$ of Asian American women collected in March 2021.

\begin{tabular}{|c|c|}
\hline Variable & $n(\%)$ \\
\hline \multicolumn{2}{|c|}{ Years of residency in the U.S. } \\
\hline Less than 30 years & $166(44.4)$ \\
\hline More than 30 years & $208(55.6)$ \\
\hline \multicolumn{2}{|c|}{ Asian sub-groups } \\
\hline Chinese American & $154(41.2)$ \\
\hline Korean American & $22(5.9)$ \\
\hline Filipino American & 59 (15.8) \\
\hline South Asian American & 51 (13.6) \\
\hline Japanese American & 40 (10.7) \\
\hline Others $^{1}$ & $36(9.6)$ \\
\hline Prefer not to answer & $12(3.2)$ \\
\hline \multicolumn{2}{|c|}{ Religion affiliation } \\
\hline Christianity & $162(43.3)$ \\
\hline Buddhism & 48 (12.8) \\
\hline Atheist & $45(12)$ \\
\hline Hinduism & $31(8.3)$ \\
\hline $\begin{array}{l}\text { Others including Islam, Judaism and other } \\
\text { categories }\end{array}$ & $88(23.6)$ \\
\hline \multicolumn{2}{|l|}{$\begin{array}{ll}\text { Residence } \\
\end{array}$} \\
\hline Rural & $28(7.5)$ \\
\hline Urban & $110(29.4)$ \\
\hline Suburban & $236(63.1)$ \\
\hline \multicolumn{2}{|c|}{ Educational attainment } \\
\hline High school graduate or less & $15(4.0)$ \\
\hline Some college or trade school & $36(9.6)$ \\
\hline Associate's degree & 46 (12.3) \\
\hline Bachelor's degree & $175(46.8)$ \\
\hline Master's degree or above & $102(27.3)$ \\
\hline \multicolumn{2}{|c|}{ Health insurance status } \\
\hline & \\
\hline No & $26(7)$ \\
\hline \multicolumn{2}{|c|}{ Household income (USD) } \\
\hline$<25,000$ & $24(6.4)$ \\
\hline $25,000-50,000$ & 65 (17.4) \\
\hline $50,001-75,000$ & $72(19.3)$ \\
\hline $75,001-100,000$ & 65 (17.4) \\
\hline$>100,000$ & $148(39.5)$ \\
\hline
\end{tabular}


Table 2. Cont.

\begin{tabular}{|c|c|}
\hline Variable & $n(\%)$ \\
\hline \multicolumn{2}{|c|}{ Marital status } \\
\hline $\begin{array}{c}\text { Married } \\
\text { Never married } \\
\text { Divorced/separated/widowed } \\
\text { Others }^{2}\end{array}$ & $\begin{array}{c}257(68.7) \\
52(13.9) \\
51(13.6) \\
14(3.8)\end{array}$ \\
\hline \multicolumn{2}{|c|}{ Employment status } \\
\hline $\begin{array}{l}\text { Yes } \\
\text { No }\end{array}$ & $\begin{array}{l}259(69.3) \\
115(30.7)\end{array}$ \\
\hline
\end{tabular}

1. Others Asian subgroups include Vietnamese American, Middle East American, and other South East Asian American.; ${ }^{2}$. Others in marital status include those in a civil union or registered domestic partnership and a member of an unmarried couple.

There were significant differences in the mean scores for all constructs of initiation and sustenance among those who have had mammography compared with those who have not had mammography. Mammography users had a statistically significant higher mean scores for initiation $(3.24 \pm 0.90$ vs. $1.63 \pm 1.2, p<0.001)$ and sustenance $(3.13 \pm 1.0$ vs. $1.23 \pm 1.1, p<0.001$ ) compared to mammography non-users (Table 3 ).

Table 3. Comparing mean scores of multi-theory model constructs of behavior change across groups of survey respondents of Asian American women.

\begin{tabular}{|c|c|c|c|c|c|c|c|}
\hline \multirow{2}{*}{$\begin{array}{c}\text { Groups } \\
\text { Constructs }\end{array}$} & \multicolumn{3}{|c|}{$\begin{array}{l}\text { Women Who Have Had Mammography } \\
\qquad(n=199)\end{array}$} & \multicolumn{4}{|c|}{ Women Who Have Not Had Mammography $(n=175)$} \\
\hline & $\begin{array}{c}\text { Possible } \\
\text { Score Range }\end{array}$ & $\begin{array}{l}\text { Observed } \\
\text { Score Range }\end{array}$ & Mean \pm SD & $\begin{array}{c}\text { Possible } \\
\text { Score Range }\end{array}$ & $\begin{array}{l}\text { Observed } \\
\text { Score Range }\end{array}$ & Mean \pm SD & $p$-Value * \\
\hline Initiation & $0-4$ & $0-4$ & $3.24 \pm 0.90$ & $0-4$ & $0-4$ & $1.63 \pm 1.2$ & $<0.001$ \\
\hline $\begin{array}{l}\text { Participatory } \\
\text { dialogue: } \\
\text { advantages }\end{array}$ & $0-20$ & $4-20$ & $17.11 \pm 2.96$ & $0-20$ & $2-20$ & $14.48 \pm 3.7$ & $<0.001$ \\
\hline $\begin{array}{l}\text { Participatory } \\
\text { dialogue: } \\
\text { disadvantages }\end{array}$ & $0-20$ & $0-20$ & $9.07 \pm 3.78$ & $0-20$ & $0-20$ & $10.62 \pm 3.46$ & $<0.001$ \\
\hline $\begin{array}{l}\text { Participatory } \\
\text { dialogue }\end{array}$ & $-20-[+20]$ & $-13-[+20]$ & $8.04 \pm 5.3$ & $-20-[+20]$ & $-12-[+20]$ & $3.86 \pm 5.36$ & $<0.001$ \\
\hline $\begin{array}{l}\text { Behavior } \\
\text { confidence }\end{array}$ & $0-20$ & $1-20$ & $14.91 \pm 3.98$ & $0-20$ & $0-20$ & $10.05 \pm 4.95$ & $<0.001$ \\
\hline $\begin{array}{l}\text { Changes in the } \\
\text { physical } \\
\text { environment }\end{array}$ & $0-12$ & $2-12$ & $10.12 \pm 2.23$ & $0-12$ & $0-12$ & $8.01 \pm 3.09$ & $<0.001$ \\
\hline Sustenance & $0-4$ & $0-4$ & $3.13 \pm 1.0$ & $0-4$ & $0-4$ & $1.23 \pm 1.1$ & $<0.001$ \\
\hline $\begin{array}{l}\text { Emotional } \\
\text { transformation }\end{array}$ & $0-12$ & $0-12$ & $9.42 \pm 2.65$ & $0-12$ & $0-12$ & $5.02 \pm 3.26$ & $<0.001$ \\
\hline $\begin{array}{l}\text { Practice for } \\
\text { change }\end{array}$ & $0-12$ & $1-12$ & $8.85 \pm 2.55$ & $0-12$ & $0-12$ & $4.82 \pm 3.14$ & $<0.001$ \\
\hline $\begin{array}{l}\text { Changes in the } \\
\text { social } \\
\text { environment }\end{array}$ & $0-20$ & $0-20$ & $13.16 \pm 4.71$ & $0-20$ & $0-20$ & $8.69 \pm 4.40$ & $<0.001$ \\
\hline
\end{tabular}

\subsection{Asian American Women Following Recommendations on Routine Mammography Screening}

Hierarchical multiple regression was performed to determine if the sequential addition of participatory dialogue, behavioral confidence, and changes in the physical environment improved the likelihood of initiation over the demographic variables of age, Asian subgroups, education, duration of U.S. residency and health insurance (Model 1). The addition of participatory dialogue to the prediction of initiation led to a statistically significant 
increase in $\mathrm{R}^{2}$ of $0.207, \mathrm{~F}(1,191)=12.113, p<0.001$ (Model 2 ). The addition of behavioral confidence to the prediction of initiation led to a statistically significant increase in $\mathrm{R}^{2}$ of $0.139, \mathrm{~F}(1,190)=19.198, p<0.001$ (Model 3). Among participants following mammography screening recommendations, the full model containing demographic variables and all three constructs to predict initiation was statistically significant, $R^{2}=0.519, F(1,189)=25.490$, $p<0.001$; adjusted $R^{2}=0.499$ (Model 4). All model results can be found in Table 4 .

Table 4. Hierarchical Multiple Regression (HRM) predicting likelihood for initiation and sustenance of mammogram behavior among survey respondents of Asian American women following recommendations on routine mammography screening $(n=199)$.

\begin{tabular}{|c|c|c|c|c|c|c|c|c|}
\hline \multirow[t]{2}{*}{ Variables } & \multicolumn{2}{|c|}{ Model 1} & \multicolumn{2}{|c|}{ Model 2} & \multicolumn{2}{|c|}{ Model 3} & \multicolumn{2}{|c|}{ Model 4} \\
\hline & B & $\beta$ & B & $\beta$ & B & $\beta$ & B & $\beta$ \\
\hline \multicolumn{9}{|c|}{ The Likelihood for initiation as a dependent variable } \\
\hline Constant & 1.936 & & 0.281 & & -0.099 & & -1.042 & \\
\hline Age & 0.005 & 0.015 & 0.020 & 0.065 & 0.013 & 0.043 & 0.019 & 0.063 \\
\hline Asian subgroups & -0.008 & -0.021 & -0.020 & -0.054 & -0.012 & -0.034 & -0.012 & -0.032 \\
\hline Education & -0.041 & -0.071 & -0.006 & -0.011 & -0.007 & -0.012 & -0.016 & -0.028 \\
\hline U.S. Residency & $0.011^{* *}$ & 0.188 & $0.009 *$ & 0.157 & 0.003 & 0.055 & 0.001 & 0.024 \\
\hline Health Insurance & $1.008 *$ & 0.163 & $1.195^{* *}$ & 0.194 & $0.921 * *$ & 0.149 & 0.784 * & 0.127 \\
\hline Participatory dialogue & & & $0.076^{* *}$ & 0.465 & $0.043 * *$ & 0.261 & $0.026 *$ & 0.156 \\
\hline Behavioral confidence & & & & & $0.096^{* *}$ & 0.439 & $0.051 * *$ & 0.236 \\
\hline $\begin{array}{l}\text { Changes in the physical } \\
\text { environment }\end{array}$ & & & & & & & $0.166^{* *}$ & 0.426 \\
\hline$R^{2}$ & 0.069 & & 0.276 & & 0.414 & & 0.519 & \\
\hline $\mathrm{F}$ & 2.840 * & & $12.113^{* *}$ & & $19.198 * *$ & & $25.490 * *$ & \\
\hline$\Delta R^{2}$ & 0.069 & & 0.207 & & 0.139 & & 0.105 & \\
\hline$\Delta \mathrm{F}$ & $2.840 *$ & & $54.521 * *$ & & $44.971^{* *}$ & & $41.145^{* *}$ & \\
\hline \multicolumn{9}{|c|}{ The Likelihood for sustenance as a dependent variable } \\
\hline Constant & 0.937 & & -0.210 & & -0.277 & & -0.368 & \\
\hline Age & 0.024 & 0.069 & 0.014 & 0.039 & 0.012 & 0.033 & 0.013 & 0.037 \\
\hline Asian subgroups & -0.004 & -0.010 & -0.021 & -0.051 & -0.019 & -0.046 & -0.020 & -0.047 \\
\hline Education & -0.010 & -0.016 & 0.012 & 0.019 & 0.008 & 0.011 & 0.008 & 0.013 \\
\hline U.S. Residency & $0.015^{* *}$ & 0.221 & 0.001 & 0.016 & 0.002 & 0.025 & 0.002 & 0.025 \\
\hline Health Insurance & 0.578 & 0.082 & 0.111 & 0.016 & 0.080 & 0.011 & 0.103 & 0.014 \\
\hline Emotional transformation & & & $0.267^{* *}$ & 0.707 & $0.168^{* *}$ & 0.447 & $0.164^{* *}$ & 0.437 \\
\hline Practice for change & & & & & $0.129^{* *}$ & 0.327 & $0.119^{* *}$ & 0.303 \\
\hline $\begin{array}{c}\text { Changes in the social } \\
\text { environment }\end{array}$ & & & & & & & 0.010 & 0.047 \\
\hline $\mathrm{R}^{2}$ & 0.066 & & 0.517 & & 0.557 & & 0.558 & \\
\hline $\mathrm{F}$ & 2.694 * & & $34.119 * *$ & & $34.128^{* *}$ & & $29.844^{* *}$ & \\
\hline$\Delta R^{2}$ & 0.066 & & 0.452 & & 0.040 & & 0.001 & \\
\hline$\Delta \mathrm{F}$ & 2.694 * & & $178.773^{* *}$ & & $17.014^{* *}$ & & 0.493 & \\
\hline
\end{tabular}

B (Unstandardized coefficient); $\beta$ (Standardized coefficient), * $p$-value $<0.05 ;{ }^{* *} p$-value $<0.001$; Adjusted $\mathrm{R}^{2}$ of initiation = 0.499; Adjusted $\mathrm{R}^{2}$ of sustenance $=0.539$.

Hierarchical multiple regression was performed to determine if the sequential addition of emotional transformation and practice for change improved the likelihood of sustenance over the demographic variables of age, Asian subgroups, education, duration of U.S. residency and health insurance (Model 1). In the hierarchical regression with sustenance as the dependent variable, the addition of emotional transformation to the prediction of sustenance led to a statistically significant increase in $\mathrm{R}^{2}$ of $0.452, \mathrm{~F}(1,191)=34.119$, $p<0.001$ (Model 2). The addition of practice for change to the prediction of sustenance led to a statistically significant increase in $\mathrm{R}^{2}$ of $0.040, \mathrm{~F}(1,190)=34.128, p<0.001$ (Model 3). The full model containing preselected demographic variables and three MTM constructs to predict sustenance was statistically significant, $\mathrm{R}^{2}=0.558, \mathrm{~F}(1,189)=29.844, p<0.001$; adjusted $R^{2}=0.539$ (Model 4 ). All model results can be found in Table 4 . 


\subsection{Asian American Women Not Following Recommendations on Routine Mammography Screening}

Among participants not following mammography screening recommendations, hierarchical multiple regression was performed to determine if the sequential addition of participatory dialogue, behavioral confidence, and changes in the physical environment improved the likelihood of initiation over the demographic variables of age, Asian subgroups, education, duration of U.S. residency and health insurance (Model 1). The addition of participatory dialogue to the prediction of initiation led to a statistically significant increase in $\mathrm{R}^{2}$ of $0.202, \mathrm{~F}(1,168)=8.185, p<0.001$ (Model 2). The addition of behavior confidence to the prediction of initiation led to a statistically significant increase in $\mathrm{R}^{2}$ of $0.090, \mathrm{~F}(1,167)=11.014, p<0.001$ (Model 3). The full model containing demographic variables and all three constructs to predict initiation was statistically significant, $R^{2}=0.319$, $F(1,166)=9.709, p<0.001$; adjusted $R^{2}=0.286$ (Model 4). All model results can be found in Table 5.

Table 5. Hierarchical Multiple Regression (HRM) predicting likelihood for initiation and sustenance of mammogram behavior among survey respondents of Asian American women not following recommendations on routine mammography screening $(n=175)$.

\begin{tabular}{|c|c|c|c|c|c|c|c|c|}
\hline \multirow[t]{2}{*}{ Variables } & \multicolumn{2}{|c|}{ Model 1} & \multicolumn{2}{|c|}{ Model 2} & \multicolumn{2}{|c|}{ Model 3} & \multicolumn{2}{|c|}{ Model 4} \\
\hline & B & $\beta$ & B & $\beta$ & B & $\beta$ & B & $\beta$ \\
\hline \multicolumn{9}{|c|}{ The Likelihood for initiation as a dependent variable } \\
\hline Constant & 1.679 & & 1.298 & & 1.196 & & 1.028 & \\
\hline Age & -0.013 & -0.029 & -0.015 & -0.033 & -0.020 & -0.043 & -0.018 & -0.039 \\
\hline Asian subgroups & 0.030 & 0.067 & 0.042 & 0.096 & 0.056 & 0.126 & 0.054 & 0.121 \\
\hline Education & 0.031 & 0.040 & 0.045 & 0.058 & 0.037 & 0.047 & 0.031 & 0.039 \\
\hline U.S. Residency & -0.002 & -0.025 & 0.000 & 0.004 & -0.007 & -0.081 & -0.007 & -0.086 \\
\hline Health Insurance & 0.444 & 0.127 & 0.318 & 0.091 & 0.161 & 0.046 & 0.173 & 0.050 \\
\hline Participatory dialogue & & & $0.098^{* *}$ & 0.452 & $0.066^{* *}$ & 0.304 & $0.064^{* *}$ & 0.294 \\
\hline Behavioral confidence & & & & & $0.082^{* *}$ & 0.350 & $0.073^{* *}$ & 0.310 \\
\hline $\begin{array}{c}\text { Changes in the physical } \\
\text { environment }\end{array}$ & & & & & & & 0.026 & 0.071 \\
\hline$R^{2}$ & 0.025 & & 0.226 & & 0.316 & & 0.319 & \\
\hline $\mathrm{F}$ & 0.852 & & $8.185^{* *}$ & & $11.014^{* *}$ & & $9.709^{* *}$ & \\
\hline$\Delta R^{2}$ & 0.025 & & 0.202 & & 0.090 & & 0.003 & \\
\hline$\Delta \mathrm{F}$ & 0.852 & & $43.772 * *$ & & $21.885^{* *}$ & & 0.704 & \\
\hline \multicolumn{9}{|c|}{ The Likelihood for sustenance as a dependent variable } \\
\hline Constant & 0.608 & & -1.312 & & -1.418 & & -1.205 & \\
\hline Age & 0.013 & 0.027 & 0.026 & 0.055 & 0.028 & 0.060 & 0.022 & 0.047 \\
\hline Asian subgroups & 0.041 & 0.091 & 0.035 & 0.078 & 0.030 & 0.066 & 0.024 & 0.054 \\
\hline Education & -0.032 & -0.040 & 0.013 & 0.016 & 0.003 & 0.004 & -0.006 & -0.007 \\
\hline U.S. Residency & -0.006 & -0.078 & $-0.016^{* *}$ & -0.192 & $-0.016^{* *}$ & -0.199 & $-0.166^{* *}$ & -0.188 \\
\hline Health Insurance & 0.265 & 0.074 & 0.268 & 0.075 & 0.276 & 0.077 & 0.213 & 0.060 \\
\hline Emotional transformation & & & $0.270 * *$ & 0.742 & $0.184^{* *}$ & 0.507 & $0.174^{* *}$ & 0.478 \\
\hline Practice for change & & & & & $0.106^{* *}$ & 0.280 & $0.072 *$ & 0.192 \\
\hline $\begin{array}{c}\text { Changes in the social } \\
\text { environment }\end{array}$ & & & & & & & 0.044 * & 0.165 \\
\hline $\mathrm{R}^{2}$ & 0.024 & & 0.557 & & 0.580 & & 0.594 & \\
\hline $\mathrm{F}$ & 0.847 & & $35.205^{* *}$ & & $32.920 * *$ & & $30.341^{* *}$ & \\
\hline$\Delta R^{2}$ & 0.024 & & 0.533 & & 0.023 & & 0.014 & \\
\hline$\Delta \mathrm{F}$ & 0.847 & & $201.956^{* *}$ & & $9.067 * *$ & & 5.744 * & \\
\hline
\end{tabular}

B (Unstandardized coefficient); $\beta$ (Standardized coefficient), * $p$-value $<0.05 ;{ }^{* *} p$-value $<0.001$; Adjusted $\mathrm{R}^{2}$ of initiation $=0.286$; Adjusted $\mathrm{R}^{2}$ of sustenance $=0.574$.

Hierarchical multiple regression was performed to determine if the sequential addition of emotional transformation and practice for change improved the likelihood of sustenance over the demographic variables of age, Asian subgroups, education, duration of U.S. residency and health insurance (Model 1). In the hierarchical regression with sustenance as a dependent variable, the addition of emotional transformation led to a statistically 
significant increase in $R^{2}$ of $0.533, \mathrm{~F}(1,168)=35.205, p<0.001$ (Model 2). The addition of practice for change to the prediction of sustenance led to a statistically significant increase in $\mathrm{R}^{2}$ of $0.023, \mathrm{~F}(1,167)=32.920, p<0.001$ (Model 3). The full model containing demographic variables and three MTM constructs to predict sustenance was statistically significant, $\mathrm{R}^{2}=0.594, \mathrm{~F}(1,166)=30.341, p<0.001$; adjusted $\mathrm{R}^{2}=0.574$ (Model 4). All model results can be found in Table 5 .

\subsection{Structural Equation Modelling}

We examined two hypothesized models. The results of the initiation model indicated the model fits the data well (e.g., $\chi^{2}[142]=304.56[p<0.01]$, CFI $=0.96$, TLI $=0.95$, and RMSEA $=0.06$ ) (Table A1). We observed the standardized effects of latent variables on their reflective indicators (i.e., factor loadings) and found an overall pattern of statistically significant loadings for advantages, disadvantages, behavioral confidence, and changes in the physical environment. The advantages had large effects (e.g., $\beta$ ranging from 0.68 to 0.91 ) on its five indicators; the disadvantages had moderate effects (e.g., $\beta$ ranging from 0.34 to 0.79 ) on its five indicators; the behavioral confidence had large effects (e.g., $\beta$ ranging from 0.74 to 0.92 ) on its five indicators; and the changes in the physical environment had large effects (e.g., $\beta$ ranging from 0.82 to 0.93 ) on its three indicators (Figure 2, Table A2). These effects suggested that our scale scores provided valid measurement of their constructs. Next, we examined between construct correlations and standardized regression coefficients. We found advantages, behavioral confidence, and changes in the physical environment had small to moderate positive direct effects on the initiation of mammography behavior (e.g., $\beta$ ranging from.16 to $0.37, p<0.001$ ), while disadvantages had small negative direct effects on the initiation of mammography behavior $(\beta=-0.13, p<0.001)$.

For the sustenance model, the fit of the model was excellent (e.g., $\chi^{2}[48]=152.98$ $[p<0.01]$, CFI $=0.97$, TLI $=0.95$, and RMSEA $=0.08)($ Table A1). We observed the standardized effects of latent variables on their reflective indicators (i.e., factor loadings) and found an overall pattern of statistically significant loadings for emotional transformation, practice for change, and changes in the social environment. The emotional transformation had large effects (e.g., $\beta$ ranging from 0.89 to 0.95 ) on its three indicators; the practice for change had large effects (e.g., $\beta$ ranging from 0.88 to 0.93 ) on its three indicators; and the changes in the social environment had moderate to large effects (e.g., $\beta$ ranging from 0.56 to 0.85 ) on its five indicators (Figure 3 , Table A3). These effects also suggested that our scale scores provided valid measurement of their constructs. We then examined between construct correlations and standardized regression coefficients for the sustenance model. We found emotional transformation had moderate direct effects on the sustenance of mammography behavior $(\beta=0.61, p<0.001)$. However, both practice for change and changes in the social environment did not have any significant effects on the sustenance of mammography behavior.

We found an overall pattern of statistically significant $(p<0.05)$ relationships among the constructs. The negative correlation between disadvantages and other factors was observed (Table 6). The Cronbach's alphas for all subscales were greater than 0.70 (ranging from 0.72 to 0.95$)$. 


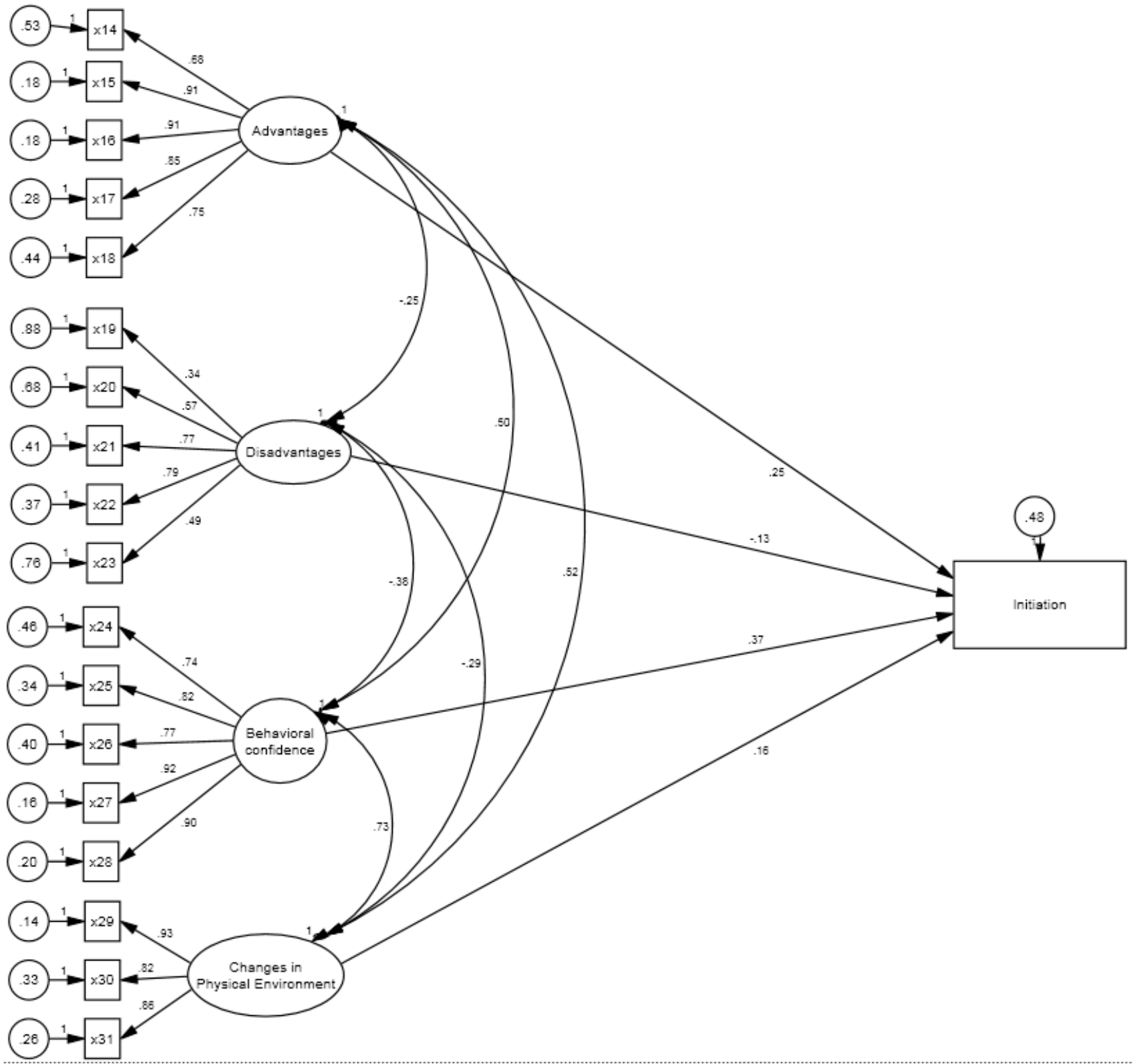

Figure 2. Structural Equation Modeling for Initiation of Mammogram Behavior among Survey Respondents of Asian American women.

Table 6. Summary of bivariate correlations, means, standard deviations, and internal consistency estimates for study variables using data from Asian American women.

\begin{tabular}{cccccccc}
\hline Variables & $\mathbf{1}$ & $\mathbf{2}$ & $\mathbf{3}$ & $\mathbf{4}$ & $\mathbf{5}$ & $\mathbf{6}$ & $\mathbf{7}$ \\
\hline 1. Advantages & - & & & & & & \\
2. Disadvantages & $-0.23^{*}$ & - & & & & & \\
3. Behavioral Confidence & $0.46^{*}$ & $-0.37^{*}$ & - & & & & \\
4. Physical Environment & $0.48^{*}$ & $-0.28^{*}$ & $0.68^{*}$ & - & & & \\
5. Emotional Transformation & $0.52^{*}$ & $-0.32^{*}$ & $0.72^{*}$ & $0.61^{*}$ & - & & \\
6. Practice for Change & $0.53^{*}$ & $-0.32^{*}$ & $0.75^{*}$ & $0.64^{*}$ & $0.88^{*}$ & - & \\
7. Changes in Social & $0.53^{*}$ & $-0.30^{*}$ & $0.65^{*}$ & $0.64^{*}$ & $0.69 *$ & $0.74 *$ & - \\
Environment & 15.88 & 9.79 & 12.64 & 9.13 & 7.36 & 6.97 & 11.07 \\
$M$ & 3.57 & 3.71 & 5.08 & 2.87 & 3.68 & 3.48 & 5.08 \\
$S D$ & 0.91 & 0.72 & 0.92 & 0.90 & 0.95 & 0.93 & 0.87 \\
$\alpha$ & & & & & & &
\end{tabular}




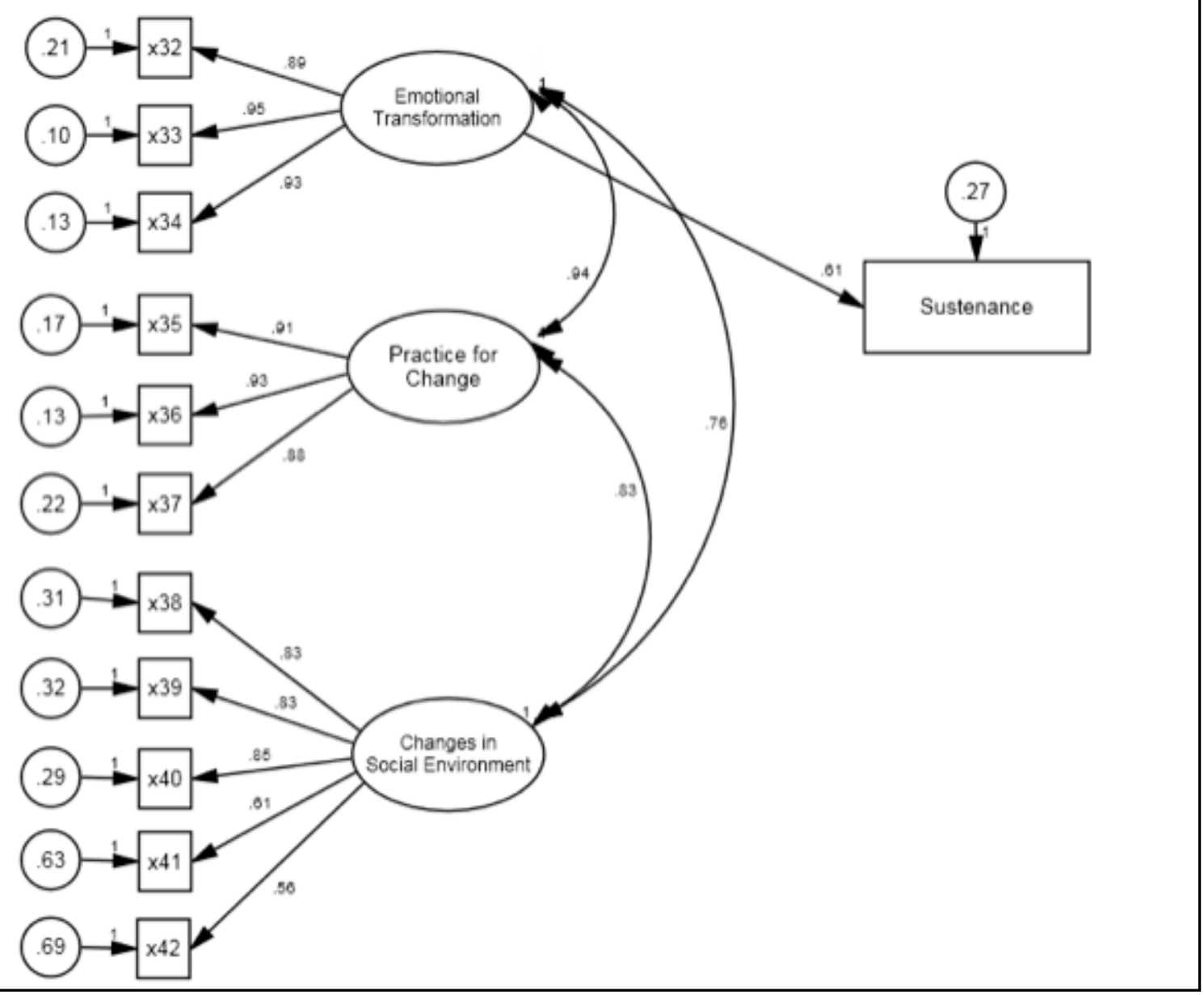

Figure 3. Structural Equation Modeling for Sustenance Model.

\section{Discussion}

The aim of this study was to explain the correlates of mammography screening using the paradigm of MTM in a nationally representative sample of Asian American women aged 45-54 years. The study found that for Asian American women

Who had received mammograms in the past 12 months as per recommendations, all three constructs of the MTM, namely, participatory dialogue $(\beta=0.156, p<0.05)$, behavioral confidence $(\beta=0.236, p<0.001)$, and changes in the physical environment $(\beta=0.426$, $p<0.001)$ were statistically significant and crucial in their decision to initiate getting the mammogram. In addition, health insurance status $(\beta=0.127, p<0.05)$ was also a significant contributor which is also supported by previous literature $[13,14]$. However, age, Asian subgroups, education, and U.S. residency were not significant contributors in the final model. The final model accounted for a substantial proportion of variance $(49.9 \%)$ in explaining the decision to receive mammography, which is considered high in social and behavioral sciences $[33,34]$. While this analysis was not necessary because this group of women were indeed adhering to the guidelines, it was conducted to confirm that the putative MTM constructs are indeed crucial in achieving the starting of the behavior. The study also found that the MTM constructs of emotional transformation $(\beta=0.437, p<0.001)$ and practice for change $(\beta=0.303, p<0.001)$ were significant for maintaining the repeated behavior of getting mammograms and were responsible for $53.9 \%$ of the variance, which again is substantial $[33,34]$. Similar significant correlates of MTM were observed in the group of Asian American women who had not received a mammogram in the past 12 months, 
where participatory dialogue $(\beta=0.294, p<0.001)$ and behavior confidence $(\beta=0.310$, $p<0.001$ ) accounted for $28.6 \%$ of the variance in the intention to get mammograms. It is worth noting that the construct of changes in physical environment which was significant for those following mammography recommendations was not significant for those not following the recommendations which is indicative of the barriers that this group may be encountering. These need to be addressed by interventions that promote mammography in Asian American women. Regarding the intention for getting repeat annual mammograms (sustenance), all MTM constructs of sustenance emotional transformation ( $\beta=0.478$, $p<0.001)$, practice for change $(\beta=0.192, p<0.05)$ changes in the social environment ( $\beta=0.165, p<0.05$ ) were significant contributors accounting for $57.4 \%$ of the variance, which is quite considerable [33,34]. It is important to note that all the constructs of MTM are significant in their putative role of explaining continuation of mammography behavior for those Asian American women not following recommendations thus underscoring the relevance of the MTM in designing interventions to promote mammography.

It is worth noting that in this nationally representative sample of Asian American women aged $45-54$ years, $46.8 \%$ of them had not received a mammogram as per the recommendations of getting one every year [11]. These findings are similar to those from the BRFSS data that found that $39.7 \%$ of Asian American women over 40 years had not received mammograms [13]. This is a sizable number of Asian American women who are not following the recommendations, underscoring the need for educational and policy efforts in promoting mammography screening to this subgroup of the population.

On close examination of each construct of MTM in its role associated with mammography screening among Asian American women aged 45-54 years old, we found several important outcomes. First, the participatory dialogue had, as expected, a significantly higher mean score $(8.04 \pm 5.3)$ among those who had received a mammogram as per recommendations compared to those who had not $(3.86 \pm 5.36)(p<0.001)$. Clearly, those who were convinced of the advantages of getting a mammography screening were motivated to get it. This is also supported by previous studies on determinants of mammography in Asian American women [14-19]. However, on hierarchical regression, the construct was found to be significant among those who were adhering to the recommendations but was not significant for those who were not adhering, after adding the construct of changes in the physical environment. This may point to the relative importance of changes in the physical environment construct which has also been supported in the literature in the form of access to health insurance $[13,14]$ or the recommendations from health care providers [17-19].

The second construct of MTM, behavioral confidence for initiating mammography screening, had the mean score that was significantly higher for those who had mammograms $(14.91 \pm 3.98)$ compared with those who had not had mammograms (10.05 \pm 4.95$)$ $(p<0.001)$. It was also a significant predictor in the regression models. Previous studies have not examined the extent of the role of this construct, as most of the studies have not utilized behavioral theories for studying determinants of mammography screening among Asian American women [17-19]. However, other studies, with other behaviors and other target populations, lend support to this construct of behavioral confidence as playing a significant role in the decision whether to seek mammograms or not [38-40].

The third MTM construct of changes in the physical environment for initiating the mammography screening had a mean score that was significantly higher for those who had mammograms $(10.12 \pm 2.23)$ compared with those who had not had mammograms $(8.01 \pm 3.09)(p<0.001)$. It was also a significant predictor in regression models. As discussed earlier, there is evidence from previous research that aspects of the physical environment are very important for Asian American women to seek mammography [13,14,17-19]. There is clearly a need to help Asian American women overcome logistical barriers that prevent them from seeking mammography screening [22].

For getting repeated annual mammograms (sustenance), the first MTM construct that was significant was emotional transformation. The mean score for this construct was significantly higher for those who had mammograms $(9.42 \pm 2.65)$ compared to those who 
had not had mammograms $(5.02 \pm 3.26)(p<0.001)$. It was also a significant predictor in the regression models. Previous studies have not examined the extent of the role of this construct in improving adherence to mammography screening recommendations among Asian American women because this is a relatively new conceptualization where feelings are purported to be used for goal setting in behavior change [33,34]. However, its role has shown to be important with other behaviors and with other target populations [37-40] so there is a need to use this construct in planning educational interventions that promote mammography screening among Asian American women.

The mean score on the construct for practice for change, which is another construct that predicts maintenance of behavior, was significantly higher for those who had mammograms $(8.85 \pm 2.55)$ compared with those who had not had mammograms $(4.82 \pm 3.14)(p<0.001)$ However, on hierarchical regression, the construct was found to be significant among those who were adhering to the recommendations but was not significant for those who were not adhering, after adding the construct of changes in the social environment. This may point to the relative importance of changes in the social environment construct which may play a greater role in the Asian American culture. The role of friends and family members and what they think is an important influence in the lives of Asian Americans. This phenomenon has not been studied extensively in relation to mammography screening among Asian American women, but Somanchi and colleagues [16] found that knowing someone with a history of breast cancer and/or having undergone mammography was a determinant in getting a mammogram for Asian American women. Therefore, this provides support to our conjecture about changes in the social environment playing a greater role. As predictable based on MTM, the mean score of the construct of changes in the social environment was also significantly higher for those who had mammograms $(13.16 \pm 4.71)$ compared with those who had not had mammograms $(8.69 \pm 4.40)(p<0.001)$. The role of this MTM construct is also supported from research with other behaviors in other target populations [38,39]. There is a need to garner support from social influences in educational programs that promote mammograms among Asian American women.

Since the Asian American community is not a monolithic entity, we collected data on the Asian subgroups. In our sample, the largest representation was from Chinese Americans $(41.2 \%)$ followed by Filipino Americans (15.8\%), followed by South Asian Americans $(13.6 \%)$ which is more or less representative of the distribution of Asian Americans in the U.S. However, we did not find any significant explanatory potential of these subgroup classifications on predicting potential utilization of mammography screening when MTM constructs are included in the modeling. Future researchers may want to reexamine it more carefully. Previous studies have noted religion, especially being a Muslim, as being a deterrent for getting mammography screening $[19,20]$. In our sample only nine $(2.4 \%)$ Asian American women practiced Islam, so we could not analyze this subgroup given the constraints of the small sample size. Future researchers may want to oversample this subgroup to discern if religion indeed is a putative determinant of mammography screening when MTM constructs are taken into consideration.

\subsection{Implications for Practice}

There is a need for both theory-based educational interventions and policy measures that promote mammography screening among Asian American women particularly in the $45-54$ age group. The educational interventions can be delivered in primary care settings, OBGYN clinics, community organizations with which Asian American women are associated, faith-based organizations specific to various religions embraced by the Asian American women community, social media, and directed mHealth interventions specifically geared toward this subgroup. MTM can serve as a promising theoretical paradigm in designing and evaluating such interventions. The construct of participatory dialogue in educational interventions can be built by underscoring advantages such as early detection of breast cancer, having peace of mind for self and family, possibility of early treatment, and reduction in premature mortality. Potential barriers such as discomfort, invasion on 
modesty, inconvenience, and fear of getting a false positive must be discussed and reduced to the extent possible in educational interventions. The construct of behavioral confidence can be fostered through exploration of sources of confidence, using role models, and using stepwise strategies in overcoming barriers. The construct of changes in the physical environment can be mobilized through resources support and reminders. The construct of emotional transformation can be channelized in educational interventions by appealing to the feelings of Asian American women and harnessing these into concrete goals of getting timely mammograms, helping overcome self-doubt, and remaining motivated. The construct of practice for change can be operationalized by encouraging Asian American women to keep records and have reminder systems, overcoming barriers, and making alternate plans if faced with obstacles. Finally, the construct of changes in the social environment must be used by educational programs where family, friends, and healthcare providers should be encouraged to promote, remind, and help with mammography screening.

\subsection{Strengths and Limitations}

This study is among the few studies that are based on a behavioral theory to decipher determinants of mammography screening in the high-risk Asian American women community. The study collected data on a nationally representative adequately powered sample representing all subgroups of Asian American women aged 45-54 years. The study utilized a contemporary fourth-generation paradigm of MTM. The psychometric validation of the tool used in the study was done meticulously. However, there were also some limitations to this study. Self-reports were utilized to collect information about mammography. Objective data using medical records could have been used to provide more accuracy. The cross-sectional nature of the design always limits causal inferences because the data on the independent variables (MTM constructs) and dependent variables (intentions) are collected at the same point in time. Future research must look into longitudinal designs. Finally, as mentioned earlier, we did not have adequate representation of the Muslim Asian American women in our sample, so we could not examine the role of MTM constructs while controlling for religion.

\section{Conclusions}

MTM is a fourth-generation behavioral theory that is gaining popularity and accumulating empirical evidence. This study is among one of those burgeoning studies that provide support to MTM. The Asian American women lag behind their White counterparts in getting screened for breast cancer and availing mammography screening, as verified by this study where almost $47 \%$ had not received the recommended mammogram in the past year. MTM-based educational and policy interventions can help Asian American women, particularly those 45-54 years old, meet the recommendations of annual mammograms thereby reducing disparities for this high-risk subgroup in the U.S. population.

Author Contributions: Conceptualization, M.S.; methodology, M.S.; K.B., C.-L.D., C.-C.C.; software, K.B., C.-L.D., C.-C.C.; validation, M.S.; K.B., C.-L.D., C.-C.C.; formal analysis, C.-L.D., C.-C.C., K.B.; investigation, M.S.; K.B., C.-L.D., C.-C.C., J.R.P., C.C., A.A., H.C.; resources, M.S., K.B., C.-L.D., C.-C.C.; data curation, M.S., K.B.; writing-M.S.; K.B., C.-L.D., C.C.C., J.P., C.C., A.A., H.C.; writingreview and editing, M.S., K.B., C.-L.D., C.-C.C., J.R.P., C.C., A.A., H.C.; visualization, K.B., C.-L.D., C.-C.C.; supervision, M.S.; project administration, M.S., K.B. All authors have read and agreed to the published version of the manuscript.

Funding: Funding for data collection was provided by the School of Public Health, University of Nevada, Las Vegas.

Institutional Review Board Statement: The study was conducted according to the guidelines of the Declaration of Helsinki and approved by the Institutional Review Board (or Ethics Committee) of the University of Nevada, Las Vegas (1727672-1 dated 4 March 2021).

Informed Consent Statement: Informed consent was obtained from all subjects involved in the study. 
Data Availability Statement: The data presented in this study are available on request from the corresponding author. The data are not publicly available due to ethical reasons.

Conflicts of Interest: The authors declare no conflict of interest.

\section{Appendix A}

Table A1. Values of Selected Fit Statistics for Hypothesized Measurement and Full Structural Models.

\begin{tabular}{cccccc}
\hline Hypothesis/Model & $\chi^{2}$ & $d f$ & RMSEA (90\% CI) & CFI & TLI \\
\hline Initiation model & $304.56^{* *}$ & 142 & $0.06(0.05-0.06)$ & 0.96 & 0.95 \\
Sustenance Model & $152.98^{* *}$ & 48 & $0.08(0.06-0.09)$ & 0.97 & 0.95 \\
\hline **
\end{tabular}
** $p<0.01$.

Table A2. Unstandardized and Standardized Parameter Estimates of Initiation Model.

\begin{tabular}{|c|c|c|c|c|c|c|}
\hline & & & $b$ & $S E$ & $p^{*}$ & $\beta$ \\
\hline \multicolumn{7}{|l|}{ Initiation Model } \\
\hline x14 & $\leftarrow$ & Advantages & 1.000 & - & - & 0.682 \\
\hline x15 & $\leftarrow$ & Advantages & 1.326 & 0.122 & $<0.001$ & 0.907 \\
\hline x16 & $\leftarrow$ & Advantages & 1.310 & 0.118 & $<0.001$ & 0.907 \\
\hline $\mathrm{x} 17$ & $\leftarrow$ & Advantages & 1.319 & 0.127 & $<0.001$ & 0.847 \\
\hline $\mathrm{x} 18$ & $\leftarrow$ & Advantages & 1.221 & 0.115 & $<0.001$ & 0.750 \\
\hline x19 & $\leftarrow$ & Disadvantages & 1.000 & - & - & 0.344 \\
\hline$\times 20$ & $\leftarrow$ & Disadvantages & 1.623 & 0.301 & $<0.001$ & 0.565 \\
\hline$x 21$ & $\leftarrow$ & Disadvantages & 2.292 & 0.393 & $<0.001$ & 0.766 \\
\hline$\times 22$ & $\leftarrow$ & Disadvantages & 2.284 & 0.399 & $<0.001$ & 0.793 \\
\hline$\times 23$ & $\leftarrow$ & Disadvantages & 1.212 & 0.234 & $<0.001$ & 0.486 \\
\hline$x 24$ & $\leftarrow$ & $\begin{array}{l}\text { Behavioral } \\
\text { Confidence }\end{array}$ & 1.000 & - & - & 0.737 \\
\hline$x 25$ & $\leftarrow$ & $\begin{array}{l}\text { Behavioral } \\
\text { Confidence }\end{array}$ & 1.072 & 0.065 & $<0.001$ & 0.815 \\
\hline$x 26$ & $\leftarrow$ & $\begin{array}{l}\text { Behavioral } \\
\text { Confidence }\end{array}$ & 1.060 & 0.065 & $<0.001$ & 0.773 \\
\hline$x 27$ & $\leftarrow$ & $\begin{array}{l}\text { Behavioral } \\
\text { Confidence }\end{array}$ & 1.180 & 0.071 & $<0.001$ & 0.915 \\
\hline$x 28$ & $\leftarrow$ & $\begin{array}{l}\text { Behavioral } \\
\text { Confidence }\end{array}$ & 1.150 & 0.065 & $<0.001$ & 0.895 \\
\hline$x 29$ & $\leftarrow$ & Physical Environment & 1.000 & - & - & 0.925 \\
\hline$\times 30$ & $\leftarrow$ & Physical Environment & 0.965 & 0.048 & $<0.001$ & 0.818 \\
\hline $\mathrm{x} 31$ & $\leftarrow$ & Physical Environment & 1.014 & 0.047 & $<0.001$ & 0.862 \\
\hline Initiation & $\leftarrow$ & Advantages & 0.594 & 0.135 & $<0.001$ & 0.249 \\
\hline Initiation & $\leftarrow$ & Disadvantages & -0.446 & 0.169 & $<0.001$ & -0.130 \\
\hline Initiation & $\leftarrow$ & $\begin{array}{l}\text { Behavioral } \\
\text { Confidence }\end{array}$ & 0.545 & 0.113 & $<0.001$ & 0.371 \\
\hline Initiation & $\leftarrow$ & Physical Environment & 0.223 & 0.102 & $<0.001$ & 0.156 \\
\hline Advantages & $\leftrightarrow$ & Disadvantages & -0.052 & 0.019 & $<0.001$ & -0.248 \\
\hline $\begin{array}{l}\text { Behavioral } \\
\text { Confidence }\end{array}$ & $\leftrightarrow$ & Advantages & 0.243 & 0.033 & $<0.001$ & 0.500 \\
\hline $\begin{array}{l}\text { Behavioral } \\
\text { Confidence }\end{array}$ & $\leftrightarrow$ & Disadvantages & -0.128 & 0.036 & $<0.001$ & -0.380 \\
\hline $\begin{array}{c}\text { Physical } \\
\text { Environment }\end{array}$ & $\leftrightarrow$ & Advantages & 0.257 & 0.032 & $<0.001$ & 0.515 \\
\hline $\begin{array}{l}\text { Physical } \\
\text { Enyironment }\end{array}$ & $\leftrightarrow$ & Disadvantages & -0.099 & 0.031 & $<0.001$ & -0.286 \\
\hline $\begin{array}{l}\text { Physical } \\
\text { Environment }\end{array}$ & $\leftrightarrow$ & $\begin{array}{l}\text { Behavioral } \\
\text { Confidence }\end{array}$ & 0.592 & 0.060 & $<0.001$ & 0.730 \\
\hline
\end{tabular}


Table A3. Unstandardized and Standardized Parameter Estimates for Sustenance Model.

\begin{tabular}{|c|c|c|c|c|c|c|}
\hline & & & $b$ & $S E$ & $p^{*}$ & $\beta$ \\
\hline \multicolumn{7}{|l|}{ Sustenance Model } \\
\hline x32 & $\leftarrow$ & $\begin{array}{c}\text { Emotional } \\
\text { Transformation }\end{array}$ & 1.000 & - & - & 0.888 \\
\hline x33 & $\leftarrow$ & $\begin{array}{c}\text { Emotional } \\
\text { Transformation }\end{array}$ & 1.126 & 0.032 & $<0.001$ & 0.947 \\
\hline x34 & $\leftarrow$ & $\begin{array}{c}\text { Emotional } \\
\text { Transformation }\end{array}$ & 1.045 & 0.035 & $<0.001$ & 0.931 \\
\hline x35 & $\leftarrow$ & Practice for Change & 1.000 & - & - & 0.909 \\
\hline x36 & $\leftarrow$ & Practice for Change & 1.007 & 0.035 & $<0.001$ & 0.932 \\
\hline x37 & $\leftarrow$ & Practice for Change & 0.935 & 0.042 & $<0.001$ & 0.884 \\
\hline$x 38$ & $\leftarrow$ & Social Environment & 1.000 & - & - & 0.831 \\
\hline x39 & $\leftarrow$ & Social Environment & 1.150 & 0.061 & $<0.001$ & 0.827 \\
\hline$x 40$ & $\leftarrow$ & Social Environment & 1.048 & 0.071 & $<0.001$ & 0.845 \\
\hline$x 41$ & $\leftarrow$ & Social Environment & 0.897 & 0.082 & $<0.001$ & 0.610 \\
\hline$\times 42$ & $\leftarrow$ & Social Environment & 0.840 & 0.084 & $<0.001$ & 0.557 \\
\hline Sustenance & $\leftarrow$ & $\begin{array}{c}\text { Emotional } \\
\text { Transformation }\end{array}$ & 0.785 & 0.173 & $<0.001$ & 0.612 \\
\hline $\begin{array}{c}\text { Emotional } \\
\text { Transformation }\end{array}$ & $\leftrightarrow$ & Practice for Change & 1.204 & 0.087 & $<0.001$ & 0.937 \\
\hline $\begin{array}{l}\text { Emotional } \\
\text { Transformation }\end{array}$ & $\leftrightarrow$ & Social Environment & 0.784 & 0.073 & $<0.001$ & 0.761 \\
\hline Practice for Change & $\leftrightarrow$ & Social Environment & 0.863 & 0.074 & $<0.001$ & 0.826 \\
\hline
\end{tabular}

* Marker variable $p$ values are from tests of standardized effect significance. $\leftarrow$ represents connections between nodes (variables). $\leftrightarrow$ indicates covariance of residuals between sets of variables.

\section{References}

1. World Health Organization. Cancer. 2021. Available online: https://www.who.int/health-topics/cancer\#tab=tab_1 (accessed on 1 May 2021).

2. Ghoncheh, M.; Pournamdar, Z.; Salehiniya, H. Incidence and mortality and epidemiology of breast cancer in the world. Asian Pac. J. Cancer Prev. 2016, 17, 43-46. [CrossRef] [PubMed]

3. DeSantis, C.E.; Ma, J.; Gaudet, M.M.; Newman, L.A.; Miller, K.D.; Goding Sauer, A.; Jemal, A.; Siegel, R.L. Breast cancer statistics, 2019. CA Cancer J. Clin. 2019, 69, 438-451. [CrossRef] [PubMed]

4. American Cancer Society. Cancer Facts E Figures 2021; American Cancer Society: Atlanta, GA, USA, 2021; Available online: https:/ / www.cancer.org/content/dam/cancer-org/research/cancer-facts-and-statistics/annual-cancer-facts-and-figures / 2021/ cancer-facts-and-figures-2021.pdf (accessed on 1 May 2021).

5. Iqbal, J.; Ginsburg, O.; Rochon, P.A.; Sun, P.; Narod, S.A. Differences in breast cancer stage at diagnosis and cancer-specific survival by race and ethnicity in the United States. JAMA 2015, 313, 165-173. [CrossRef]

6. Morey, B.N.; Gee, G.C.; von Ehrenstein, O.S.; Shariff-Marco, S.; Canchola, A.J.; Yang, J.; Gomez, S.L. Higher breast cancer risk among immigrant Asian American women than among US-born Asian American women. Prev. Chronic Dis. 2019, 16, E20. [CrossRef] [PubMed]

7. Wu, T.Y.; Ronis, D. Correlates of recent and regular mammography screening among Asian-American women. J. Adv. Nurs. 2009, 65, 2434-2446. [CrossRef] [PubMed]

8. Parise, C.; Caggiano, V. Breast Cancer Mortality among Asian-American Women in California: Variation according to Ethnicity and Tumor Subtype. J. Breast Cancer 2016, 19, 112-121. [CrossRef]

9. Centers for Disease Control and Prevention. What Is Breast Cancer Screening? 2020. Available online: https://www.cdc.gov/ cancer/breast/basic_info/screening.htm (accessed on 1 May 2021).

10. Løberg, M.; Lousdal, M.L.; Bretthauer, M.; Kalager, M. Benefits and harms of mammography screening. Breast Cancer Res. 2015, 17, 63. [CrossRef] [PubMed]

11. American College of Obstetricians and Gynecologists. Breast cancer risk assessment and screening in average-risk women. Practice Bulletin Number 179. Obstet. Gynecol. 2017, 130, e1-e16. [CrossRef] [PubMed]

12. Lee, M.H.; Merighi, J.R.; Lee, H.Y. Factors associated with mammogram use in Korean American immigrant women. Am. J. Health Behav. 2019, 43, 1075-1085. [CrossRef]

13. Oh, K.M.; Zhou, Q.P.; Kreps, G.L.; Ryu, S.K. Breast cancer screening practices among Asian Americans and Pacific Islanders. Am. J. Health Behav. 2012, 36, 711-722. [CrossRef]

14. Chawla, N.; Breen, N.; Liu, B.; Lee, R.; Kagawa-Singer, M. Asian American women in California: A pooled analysis of predictors for breast and cervical cancer screening. Am. J. Public Health 2015, 105, e98-e109. [CrossRef]

15. De Alba, I.; Hubbell, F.A.; McMullin, J.M.; Sweningson, J.M.; Saitz, R. Impact of U.S. citizenship status on cancer screening among immigrant women. J. Gen. Intern. Med. 2005, 20, 290-296. [CrossRef] 
16. Somanchi, M.; Juon, H.S.; Rimal, R. Predictors of screening mammography among Asian Indian American women: A crosssectional study in the Baltimore-Washington metropolitan area. J. Womens Health 2010, 19, 433-441. [CrossRef]

17. Boxwala, F.I.; Bridgemohan, A.; Griffith, D.M.; Soliman, A.S. Factors associated with breast cancer screening in Asian Indian women in metro-Detroit. J. Immigr. Minor. Health 2010, 12, 534-543. [CrossRef]

18. Kagawa-Singer, M.; Pourat, N.; Breen, N.; Coughlin, S.; Abend McLean, T.; McNeel, T.S.; Ponce, N.A. Breast and cervical cancer screening rates of subgroups of Asian American women in California. Med. Care Res. Rev. 2007, 64, 706-730. [CrossRef]

19. Padela, A.I.; Murrar, S.; Adviento, B.; Liao, C.; Hosseinian, Z.; Peek, M.; Curlin, F. Associations between religion-related factors and breast cancer screening among American Muslims. J. Immigr. Minor. Health 2015, 17, 660-669. [CrossRef] [PubMed]

20. Padela, A.I.; Vu, M.; Muhammad, H.; Marfani, F.; Mallick, S.; Peek, M.; Quinn, M.T. Religious beliefs and mammography intention: Findings from a qualitative study of a diverse group of American Muslim women. Psychooncology 2016, 25, 1175-1182. [CrossRef] [PubMed]

21. Pourat, N.; Kagawa-Singer, M.; Breen, N.; Sripipatana, A. Access versus acculturation: Identifying modifiable factors to promote cancer screening among Asian American women. Med. Care 2010, 48, 1088-1096. [CrossRef] [PubMed]

22. Miller, B.C.; Bowers, J.M.; Payne, J.B.; Moyer, A. Barriers to mammography screening among racial and ethnic minority women. Soc. Sci. Med. 2019, 239, 112494. [CrossRef]

23. Battaglia, T.A.; Roloff, K.; Posner, M.A.; Freund, K.M. Improving follow-up to abnormal breast cancer screening in an urban population. A patient navigation intervention. Cancer 2007, 109, 359-367. [CrossRef]

24. Berger, S.; Huang, C.C.; Rubin, C.L. The role of community education in increasing knowledge of breast health and cancer: Findings from the Asian Breast Cancer Project in Boston, Massachusetts. J. Cancer Educ. 2017, 32, 16-23. [CrossRef]

25. Dang, J.; Lee, J.; Tran, J.H.; Kagawa-Singer, M.; Foo, M.A.; Nguyen, T.U.; Valdez-Dadia, A.; Thomson, J.; Tanjasiri, S.P. The role of medical interpretation on breast and cervical cancer screening among Asian American and Pacific Islander women. J. Cancer Educ. 2010, 25, 253-262. [CrossRef] [PubMed]

26. Keshinro, A.; Hatzaras, I.; Rifkind, K.; Dhage, S.; Joseph, K.A. The impact of primary care providers on patient screening mammography and initial presentation in an underserved clinical setting. Ann. Surg. Oncol. 2017, 24, 692-697. [CrossRef] [PubMed]

27. Padela, A.I.; Malik, S.; Ally, S.A.; Quinn, M.; Hall, S.; Peek, M. Reducing Muslim mammography disparities: Outcomes from a religiously tailored mosque-based intervention. Health Educ. Behav. 2018, 45, 1025-1035. [CrossRef] [PubMed]

28. Padela, A.I.; Malik, S.; Din, H.; Hall, S.; Quinn, M. Changing mammography-related beliefs among American Muslim women: Findings from a religiously tailored mosque-based intervention. J. Immigr. Minor. Health 2019, 21, 1325-1333. [CrossRef]

29. Sadler, G.R.; Beerman, P.R.; Lee, K.; Hung, J.; Nguyen, H.; Cho, J.; Huang, W. Promoting breast cancer screening among Asian American women: The Asian grocery store-based cancer education program. J. Cancer Educ. 2012, 27, 612-617. [CrossRef] [PubMed]

30. Lee, E.E.; Brecht, M.L.; Park, H.; Lee, J.; Oh, K.M. Web-based study for improving mammography among Korean American women. J. Cancer Educ. 2017, 32, 257-263. [CrossRef] [PubMed]

31. Wu, T.Y.; West, B.T. Mammography stage of adoption and decision balance among Asian Indian and Filipino American women. Cancer Nurs. 2007, 30, 390-398. [CrossRef]

32. Sun, Y.; Sarma, E.A.; Moyer, A.; Messina, C.R. Promoting mammography screening among Chinese American women using a message-framing intervention. Patient Educ. Couns. 2015, 98, 878-883. [CrossRef]

33. Sharma, M. Multi-theory model (MTM) for health behavior change. WebmedCentral Behav. 2015, 6, WMC004982. Available online: http:/ / www.webmedcentral.com/article_view/4982 (accessed on 6 April 2021).

34. Sharma, M. Theoretical Foundations of Health Education and Health Promotion, 4th ed.; Jones and Bartlett: Burlington, MA, USA, 2021; pp. 250-262. ISBN 978-1284208627.

35. Agyei-Baffour, P.; Asare, M.; Lanning, B.; Koranteng, A.; Millan, C.; Commeh, M.E.; Montealegre, J.R.; Mamudu, H.M. Human papillomavirus vaccination practices and perceptions among Ghanaian healthcare providers: A qualitative study based on multi-theory model. PLOS ONE 2020, 15, e0240657. [CrossRef]

36. Mousali, A.; Moradveisi, L.; Barati, M.; Moeini, B.; Bashirian, S.; Sharma, M.; Mohammadi, Y. Male addicts' experiences on predictors of relapse to drug use: A directed qualitative content analysis. Addicta Turk. J. Addict. 2020, 7, 166-173. [CrossRef]

37. Asare, M.; Agyei-Baffour, P.; Lanning, B.A.; Owusu, A.B.; Commeh, M.E.; Boozer, K.; Koranteng, A.; Spies, L.A.; Montealegre, J.R.; Paskett, E.D. Multi-theory model and predictors of likelihood of accepting the series of HPV vaccination: A cross-sectional study among Ghanaian adolescents. Int. J. Environ. Res. Public Health 2020, 17, 571. [CrossRef] [PubMed]

38. Sharma, M.; Largo-Wight, E.; Kanekar, A.; Kusumoto, H.; Hooper, S.; Nahar, V.K. Using the multi-theory model (MTM) of health behavior change to explain intentional outdoor nature contact behavior among college students. Int. J. Environ. Res. Public Health 2020, 17, 6104. [CrossRef]

39. Sharma, M.; Batra, K.; Davis, R.; Wilkerson, A. Explaining handwashing behavior among college students during COVID-19 pandemic using the multi-theory model (MTM) of health behavior change. Healthcare 2021, 9, 55. Available online: https: / / www.mdpi.com/2227-9032/9/1/55 (accessed on 1 May 2021). [CrossRef]

40. Williams, J.L.; Sharma, M.; Mendy, V.L.; Leggett, S.; Akil, L.; Perkins, S. Using multi theory model (MTM) of health behavior change to explain intention for initiation and sustenance of the consumption of fruits and vegetables among African American men from barbershops in Mississippi. Health Promot. Perspect. 2020, 10, 200-206. [CrossRef] 
41. Bashirian, S.; Barati, M.; Sharma, M.; Abasi, H.; Karami, M. Water pipe smoking reduction in the male adolescent students: An educational intervention using multi-theory model. J. Res. Health Sci. 2019, 19, e00438.

42. Brown, L.; Sharma, M.; Leggett, S.; Sung, J.H.; Bennett, R.L.; Azevedo, M. Efficacy testing of the SAVOR (Sisters Adding Fruits and Vegetables for Optimal Results) intervention among African American women: A randomized controlled trial. Health Promot. Perspect. 2020, 10, 270-280. [CrossRef]

43. Hayes, T.; Sharma, M.; Shahbazi, M.; Sung, J.H.; Bennett, R.; Reese-Smith, J. The evaluation of a fourth-generation multi-theory model (MTM) based intervention to initiate and sustain physical activity in African American women. Health Promot. Perspect. 2019, 9, 13-23. [CrossRef]

44. Qualtrics Market Research Panel Survey. 2021. Available online: https:/ / www.qualtrics.com/market-research/ (accessed on 1 May 2021).

45. Miller, C.A.; Guidry, J.P.D.; Dahman, B.; Thomson, M.D. A tale of two diverse Qualtrics samples: Information for online survey researchers. Cancer Epidemiol. Biomark. Prev. 2020, 29, 731-735. [CrossRef]

46. Cohen, J. Statistical Power Analysis for the Behavioral Sciences, 2nd ed.; Lawrence Erlbaum Associates: Mahwah, NJ, USA, 1988; ISBN 0-8058-0283-5. Available online: http:/ / utstat.toronto.edu/ \{\}brunner/oldclass/378f16/readings/CohenPower.pdf (accessed on 1 May 2021).

47. Faul, F.; Erdfelder, E.; Buchner, A.; Lang, A.G. Statistical power analyses using G*Power 3.1: Tests for correlation and regression analyses. Behav. Res. Methods 2009, 41, 1149-1160. [CrossRef]

48. Bollen, K.A. A new incremental fit index for general structural equation models. Socio. Methods. Res. 1989, 17, 303-316. [CrossRef]

49. Byrne, B.M. Structural Equation Modeling with AMOS: Basic Concepts, Applications, and Programming, 2nd ed.; Routledge Taylor \& Francis Group: New York, NY, USA, 2001; ISBN 978-0-8058-6372-7.

50. Hu, L.; Bentler, P.M. Cutoff criteria for fit indexes in covariance structure analysis: Conventional criteria versus new alternatives. Struc. Equ. Model. Multidiscp. J. 1999, 6, 1-55. [CrossRef]

51. Browne, M.W.; Cudeck, R. Alternative Ways of Assessing Model fit. In Testing Structural Equation Models; Bollen, K.A., Long, J.S., Eds.; SAGE Publications: Newbury Park, UK, 1993; pp. 136-162. ISBN 978-0803945074.

52. Nunnally, J.C. Psychometric Theory; McGraw-Hill: New York, NY, USA, 1967.

53. Lipsey, M.W.; Wilson, D.B. The efficacy of psychological, educational, and behavioral treatment: Confirmation from meta-analysis. Am. Psychol. 1993, 48, 1181-1209. [CrossRef]

54. Sharma, M.; Petosa, R.L. Measurement and Evaluation for Health Educators, 1st ed.; Jones \& Bartlett Learning: Burlington, MA, USA, 2014.

55. Soper, D.S. A-Priori Sample Size Calculator for Structural Equation Models [Software]. 2021. Available online: https://www. danielsoper.com/statcalc (accessed on 3 April 2021).

56. Hoyle, R.H.; Gottfredson, N.C. Sample Size Considerations in Prevention Research Applications of Multilevel Modeling and Structural Equation Modeling. Prev. Sci. 2015, 16, 987-996. [CrossRef] [PubMed]

57. Muthén, L.K.; Muthén, B.O. How to use a Monte Carlo study to decide on sample size and determine power. Struct. Equ. Modeling APA PsycNet. 2002, 9, 599-620. [CrossRef]

58. Wolf, E.J.; Harrington, K.M.; Clark, S.L.; Miller, M.W. Sample Size Requirements for Structural Equation Models: An Evaluation of Power, Bias, and Solution Propriety. Educ. Psychol. Meas. 2013, 76, 913-934. [CrossRef] 